\title{
Erythema multiforme triggered by a spider bite in an adult female patient
}

\section{Nadia Nabli, Lobna Boussofara, Nadia Ghariani Fetoui, Colandane Belajouza, Mohamed Denguezli}

Department of Dermatology, Hospital Farhat Hached Sousse, Tunisia

Corresponding author: Dr. Nadia Nabli, E-mail: nablinadya@gmail.com

\begin{abstract}
Erythema multiforme $(\mathrm{EM})$ is an immune-mediated eruption characterized by acral targetoid lesions that is due mostly to an infection particularly herpes and Mycoplasma infections. A 26-year-old woman presented with a necrotic erythematous lesion under her right breast and an erythematous and targetoid lesions on the distal parts of her extremities following a spider bite. She had not used any medication and she gave no prior history of herpetic infection. We imputed the spider bite as the cause of EM based upon the clinical history and the laboratory tests that failed to implicate another cause of EM. As far as we know, this is the second reported case of EM induced by a spider bite. We suggest that Loxosceles spider bites may cause erythema multiforme.
\end{abstract}

Key words: Erythema multiforme; Spider bite; Loxoscelism

\section{INTRODUCTION}

Erythema multiforme (EM) is an immune-mediated condition characterized by erythematous plaques or papules that evolve into targetoid lesions distributed mostly on the distal parts of the extremities $[1,2]$. EM is due to an infection in more than $90 \%$ of cases particularly herpes and Mycoplasma infections. Drug intake is implicated in fewer than $10 \%$ of cases [1]. EM may also be caused by fungal infections, neoplasms, connective tissue disorders, or it may be idiopathic [2]. Here we report a patient presenting with EM lesions following a spider bite.

\section{CASE REPORT}

A 26-year-old female patient, with no history of recurrent infections, presented with an acral rash that appeared 5 days after being bitten by a small and shiny blackcolored spider on the trunk that she saw but she did not capture it. Physical examination revealed targetoid acral papules (Figs. 1 and 2) with no mucosal involvement and an inflammatory plaque under the right breast centered by two necrotic bullous lesions (Fig 3). General laboratory analysis was negative. Serological detection tests for Mycoplasma pneumoniae, anti-HIV antibodies and anti-HSV type 1 and 2 antibodies of both immunoglobulin $(\mathrm{Ig}) \mathrm{M}$ and $\mathrm{Ig} \mathrm{G}$ types were negative. We imputed the spider bite as the cause of EM based upon the clinical history and the laboratory tests that failed to implicate another cause of EM. The patient received topical Betamethasone Dipropionate 0,05\% on the acral lesions and local wound care of the spider bite site, with a favourable course.

\section{DISCUSSION}

Spider bites are frequent, but most domestic spiders are not harmful for humans as they typically cause minor symptoms such as pruritic and small pink papules [3]. Rarely, fatal systemic immunologic reactions and severe local lesions occur [4]. These systemic reactions may result from some species commonly found in the Mediterranean basin. The most frequently involved spiders arise from the genus Loxosceles [5]. The local lesion of the spider bite is initially painless and may

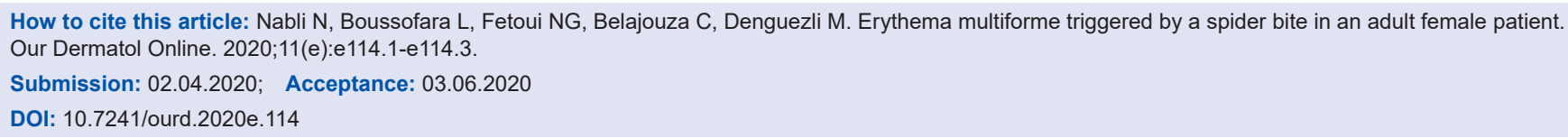




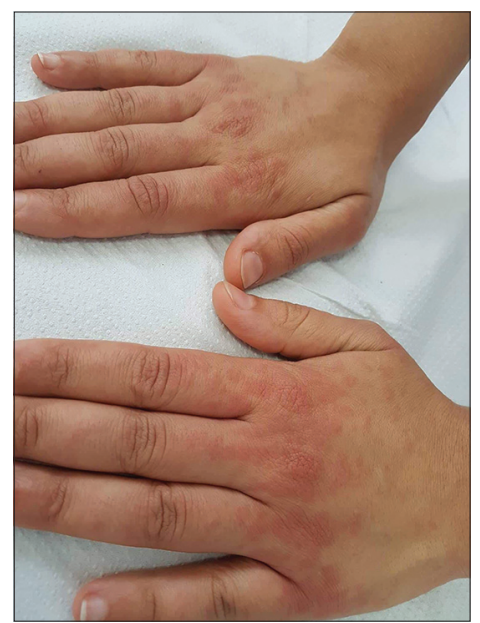

Figure 1 : Erythematous targetoid papules on the hands.

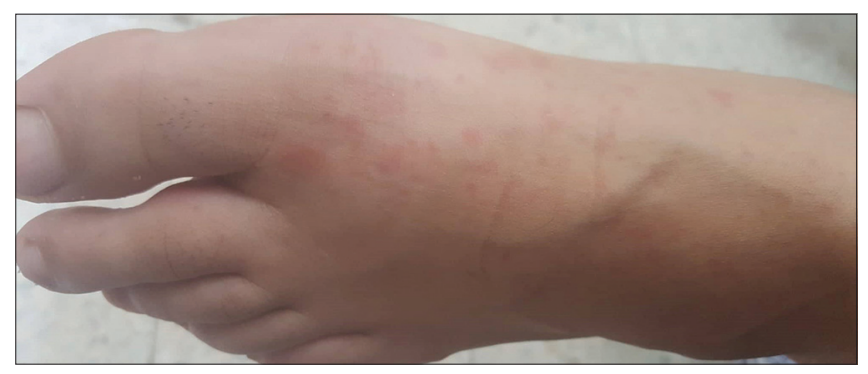

Figure 2: Erythematous targetoid papules on the foot.

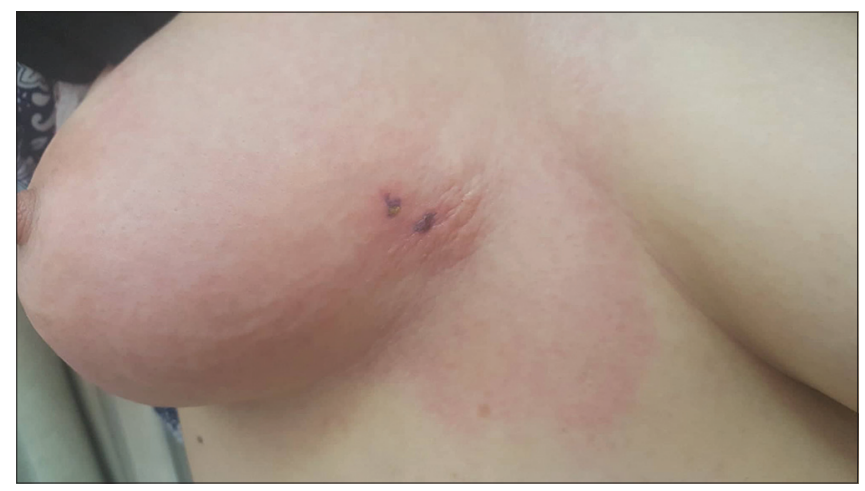

Figure 3: Necrotic bullous lesions under the right breast corresponding to the spider bite.

easily be overlooked by the patient [6]. Lesions may be mild, moderate, or severe depending upon the presence and degree of necrosis. Moderate lesions - as in this case-are the most common [7]. Apart from local lesions, the skin reaction to a spider bite may present as a maculopapular eruption over the entire body which has been reported in $5-32 \%$ of the published cases [2]. Acute generalized exanthematous pustulosis (AGEP) and pustular skin reactions have also been described $[4,8]$. A case of a drug reaction with eosinophilia and systemic symptoms (DRESS) syndrome and few cases of cutaneous manifestations of systemic lupus attributed to a spider bite have also been reported $[9,10]$. EM is most likely an immune mediated mucocutaneous eruption that occurs in predisposed individuals [11]. EM usually appears in the setting of infection such as herpes simplex virus (HSV1 or HSV2) or Mycoplasma pneumoniae, but it may also be idiopathic [12]. Lesions mostly occur in a symmetric, acral distribution and may remain fixed at the same site for 7 days or more [2]. In our case, the clinical history combined with the typical skin lesions confirmed the diagnosis of EM. The laboratory tests eliminated other etiologies of EM. Hence, we could implicate the spider bite in its occurrence. There is one case of EM triggered by a spider bite reported in the literature [2]. The diagnosis was also established based on the clinical history and laboratory findings. Here, we present the second case.

\section{CONCLUSION}

We suggest that Loxosceles spider bites may cause erythema multiforme.

\section{Consent}

The examination of the patient was conducted according to the Declaration of Helsinki principles.

The authors certify that they have obtained all appropriate patient consent forms. In the form the patient(s) has/have given his/her/ their consent for his/her/their images and other clinical information to be reported in the journal. The patients understand that their names and initials will not be published and due efforts will be made to conceal their identity, but anonymity cannot be guaranteed.

\section{REFERENCES}

1. Coates SJ, Briggs B, Cordoro KM. Tularemia-induced erythema multiforme minor in an 11-year-old girl. Pediatr Dermatol. 2018;35:478-81.

2. Özyurt S, Er O, Afsar FS, Ermete M. Spider bite-induced erythema multiforme. Cutan Ocul Toxicol. 2013;32:255-7.

3. Ahmed S, Bromberek E, Borhart J. Exaggerated arthropod bite: a case report and review of the mimics. Clin Pract Cases Emerg Med. 2018;2:58-60.

4. Ermertcan AT, Demirer O, Inanir I, Bilaç C, Temiz P. Acute generalized exanthematous pustulosis with lymphangitis triggered by a spider bite. Cutan Ocul Toxicol. 2010;29:67-9.

5. GremskiLH, Trevisan-Silva D, FerrerVP, Matsubara FH, MeissnerGO, Martins Wille AC, et al. Recent advances in the understanding of brown spider venoms: From the biology of spiders to the molecular mechanisms of toxins. Off J Int So Toxinol. 2014;83:91-120.

6. Cachia M, Mercieca L, Mallia Azzopardi C, Boffa MJ. Rare case of dermonecrosis caused by a recluse spider bite in Europe. BMJ Case Rep. 2016;2016:bcr2016215832.

7. Dyachenko P, Ziv M, Rozenman D. Epidemiological and clinical manifestations of patients hospitalized with brown recluse spider 


\section{www.odermatol.com}

bite. J Eur Acad Dermatol Venereol. 2006;20:1121-5.

8. Ben Said Z, Saidi W, Boussofara L, Ghariani N, Belajouza C, Sriha B, et al. Pustulose exanthématique aiguë généralisée succédant à une morsure d'araignée : trois observations tunisiennes. Ann Dermatol Vénéréologie. 2010;137:813-8.

9. Eyraud A, Boursault L, Darrigade A-S, Taieb A, Milpied B. First case of DRESS syndrome attributed to a spider bite. J Allergy Clin Immunol Pract. 2017;5:1135-6.

10. Martín Nares E, López Iñiguez A, Ontiveros Mercado H. Systemic lupus erythematosus flare triggered by a spider bite. Jt Bone Spine Rev Rhum. 2016;83:85-7.

11. Lucchese A. From HSV infection to erythema multiforme through autoimmune crossreactivity. Autoimmun Rev. 2018;17:576-81.

12. Kechichian E, Ingen-Housz-Oro S, Sbidian E, Hemery F, Bernier C, Fite $\mathrm{C}$, et al. A large epidemiological study of erythema multiforme in france, with emphasis on treatment choices. Br J Dermatol. 2018;179:1009-11.

Copyright by Nadia Nabli, et al. This is an open access article distributed under the terms of the Creative Commons Attribution License, which permits unrestricted use, distribution, and reproduction in any medium, provided the original author and source are credited.

Source of Support: Nil, Conflict of Interest: None declared. 